\title{
Informatization Literacy in Medical College Students
}

\author{
Na Wang ${ }^{1}$ and Jinguo Wang, ${ }^{2, *}$ \\ ${ }^{1}$ Department of Anesthesiology, The First Hospital of Jilin University, China \\ ${ }^{2}$ Department of Urology, The First Hospital of Jilin University, China \\ ${ }^{*}$ Corresponding author
}

\begin{abstract}
The number of medical documents has increased sharply. The content is rich and the form is constantly updated. The service method of medical information has been developed and expanded extensively. The management of medical information tends to be open and used independently. In the environment of medical modern informatization, medical college students have many obstacles and shortcomings in informatization awareness and skills of privacy protection. This paper makes a comprehensive analysis of subjective and objective causes of the problem, cultivates the students' informatization literacy of medical records. The students' informatization literacy should play a more important role in the point of view of the whole medical informatization.
\end{abstract}

Keywords-information; literacy; education; medicine; college

\section{INTRODUCTION}

There are many problems associated with medical informatization, such as intellectual rights of medical digital research, the doctor-patient relationship, effective protection of privacy, difficulties of the informed consent, hidden dangers of information and network security, the embarrassment of remote medical service, medical defects in the digital system, network disputes, and so on. The proper solution to these problems can help medical informatization develop in a healthy and beneficial direction, which can well serve human health. It involves ethical issues and becomes more and more serious. If these problems don't be solved in time, it will directly affect the development of medical informatization. [1]

\section{INFORMATIZATION LITERACY}

\section{A. The Concept of Informatization Literacy}

The concept of informatization literacy is a hierarchical information quality requirements for different groups which can't completely unified. People of different professional disciplines and the education levels of the information quality have the characteristics of their respective, connotation and evaluation standard.

The construction of medical informatization is a long-term job. Only if the medical informatization accords with the ethical requirement, it has vitality. It has very important practical significance and long-term significance. We can see not only large digital medical equipments widely used in the hospital, but also various medical charge systems, computer network management systems and medical information processing system which are very popular. Information technology begins to be used in medical teaching and scientific research to improve the teaching and the scientific research level. [2]
Information technology brings new cognitive channels, ideas and methods to medicine science. The information technology is used to transform many traditional practices and constantly innovate the medical field. [3] In the 21st century, Chinese medical colleges and universities must push forward informatization as the deepening of education teaching reform, improve the quality of talent training, and make the important way for modern medical talents. [4]

\section{B. The Concept of Informatization Ethics}

Based on the important role of ethics in the medical field, as well as the purpose of ethics, the discussion of rights and obligations of ethics puts forward the principle of equality and justice. According to the principle of compatibility, reciprocity, informed consent and harmless medical ethics, lessons are drawn from some famous network specification and put forward the medical information ethics. [5]

The information technology is a new technology and means, and the medical students need a process to know and apply it. Most medical students don't know enough about the potential drawbacks and problems of information technology. The medical college should spare effort to strengthen education. The adoption of new technology is not to reduce doctors' responsibilities, but to double duty and care. [6]

\section{ESTABLISHMENT OF INFORMATIZATION LITERACY}

The improvement of college students' information ability is not just by internal education systems, because it has not a pure education problem. Therefore, the cultivation of college students' information ability also calls for the social widespread support.

In the information age and the rapid development of modern information technology, it is a necessary skill to master and use the information needed to solve practical problems. Medical college students are referred as the wealth of the society and hope for the future of the world, so they must adapt to the development requirement of the society. They must have the high information quality in the future society. [7]

The literature review course in colleges and universities is an effective way to improve information quality of medical college students. This paper points out that the literature retrieval course improves college students' information literacy by carrying out the information literacy education from the definition, education connotation and the significance of information literacy in colleges and universities. 


\section{A. Literature Review Course}

The history teaching and literature review course are very important in China. The investigation and comprehensive analysis, combined with the existing problems and the actual situation expounds the research methods. The present situation of literature retrieval course in colleges and universities through specific argument puts forward the teaching. The traditional literature retrieval course teaching couldn't keep up with the pace of development in the information age, so teaching reform is imperative. [8] Finally, based on the information quality of medical college students, this paper discusses the concrete measures of the teaching reform of literature review course.

The theory study on the reform of literature review course, which has the real academic value and practical application significance, can improve the information literacy of university students, promote their success in the future in the society and create more benefit for country.

With the rapid development of science and technology, human society is moving forward at an unprecedented speed. On the basis of the knowledge economy, information network as the carrier of information learning society is emerging. [9]

Information quality as an important part of human's overall quality is the basic condition of people's survival and development in the information society.

Information quality education, as a conscious, purposeful and planned way fosters the quality of information literacy. Education activities can help people adapt to the information society life, study and work. It improves the ability of people survival and development of the learning society of informatization. It has very important significance.

This paper focuses on the information quality of undergraduates in higher medical colleges and probes into the information quality of this particular group education.

\section{B. The Core Objective of Medical Education Informatization}

The core objective of education informatization is to promote the organic integration of modern information technology, medical teaching practice and establish a new education teaching mode and train medical informatization talents.

To achieve this, in the present stage, the institutions of higher education should begin with the supporting system construction for education resource development. It has some key links to increase the intensity of construction and lay a necessary foundation for the comprehensive education informatization. [10]

It mainly combines the characteristics of medical personnel training and the construction of the network environment. We divided the new teaching model into instructional learning WST and research-learning WST which can explain the main process of the new mode. [11]

WST which is built in the network environment and on the base of modern information technology, embodies the modern learning theory and instructional design theory of ideas. It strengthens the medical students' comprehensive quality and ability training, especially the self-study ability, information ability and innovation ability.

\section{INFORMATION MANAGEMENT}

The application of information management evaluation for ethical review work improves the quality of work quality and efficiency, further standardizes the ethical review work, also helps to protect the privacy of the subjects in medical research, and establishes the medical research ethics review information system.

Therefore, on the base of the experience of informatization construction and through the establishment of ethical review information and tracking system, it can set up the information rights management system of electronic signature. by building the continuing education training and establishing a communication platform with the principal investigator, the medical research ethics review information system is built and perfected. [12]

\section{A. Evaluation System}

To ensure the healthy development of education informatization, special education evaluation must be strengthened. To achieve this goal, we try to determine evaluation index, using the pairwise comparison distribution and the matrix synthesis processing evaluation data. We try to set up comprehensive evaluation model of college education informatization stages according to the factorization method.

With the fast development of Chinese medical and health informatization and the clinical application of informatization system, the remote medical treatment is gradually mature and tends to be a more intelligent process. At the same time, the hidden danger in network security, leaks, illegal profit, and the problem of violation of medical ethics reduce the patient satisfaction and trust. Harm in different degrees to the patients group set up the overall image of the modern high-tech medical informatization in our country .

It is necessary to strengthen health information network security monitoring, research and improvement of national and local relevant health informatization. The construction of the rule of law, in accordance with the effective remote consultation information prevents the risk. We must stop the information data leaked by the medical institutions for the purpose of obtaining improper benefits. [13]

In accordance with the law, it bans the false, medical electronic networks with fraudulent information, medical advertising, sillegal behavior, so that the construction of the medical and health information systems is toward a more perfect, healthy and high-speed development.

\section{B. The Network Environment}

The network environment and application of modern information technology in education are also discussed. In this way, people have a new and higher understanding of the conditions of medical treatment and the need to achieve the ideal healthy state. People have become more and more receptive to the treatment of minimally invasive surgery.

All kinds of large medical equipment gather in the intervention of modern digital operating room in the process of 
interventional surgery related to patients with a large number of images, video and other imaging data.

It not only exposes patients with the private parts of the body in the process of interventional diagnosis and treatment. However, it involves more invasive surgery in the intervention operation in the process of imaging information data which is the so-called privacy. [14]

As a non-general group, patients' legal awareness of personal privacy protection has been gradually enhanced, and their privacy protection has become the focus of public opinion.

Teaching important working content and mode are through the target, content, four aspects of the embedded environment and mechanism. It implements around innovative scientific workflow to support scientific research, professional education and learning library service work. It is with the tools of advanced technology, and digital environment and related knowledge services which are necessary to develop a close coupling with system and collaborative and interactive information literacy education.

Analysis of national science library, Chinese academy of sciences, the information quality education service system and Harvard University teaching support service shows that information quality education is a kind of integrated into the process and problem oriented education mode.

\section{Figures and Tables}

With the continuous development of Chinese social economy, informatization and digitalization have entered various fields of medicine and become indispensable means and tools for now.

Information technology is changing medical science from the teaching and scientific research to many traditional ways of medical service. We can see a hospital from single to various medical charge system. Computer network management system and medical information processing systems are popular. The MRI, CT, DSA and digital medical equipment are widely used in hospitals, medical teaching and research areas which are beginning to use information technology to improve the teaching and scientific research level.

Medical institutions are becoming more digitized and informationalized. Medical institutions are rapidly introducing large-scale digital medical devices and interventional diagnosis and treatment technologies to the public.

Information technology brings new cognitive channels, ideas and working methods to medicine, and the medical field is using information technology to transform many traditional practices.

On the basis of the research of influential open information literacy education website content, function and style, the United States website features a more in-depth evaluation, respectively the website of guiding ideology, content, organization, content selection and settings. Web pages show the comparison between the United States and China.

Information quality education in China, which has the increased publicity, plays special advantage, strengthens the thinking innovation training of users, so they can finely process knowledge content, strengthen the self-test function, enhance the vitality of the web forms and diversity of domestic open information quality education from the perspectives of the website construction of thinking and suggestion.

\section{SUMMARY}

This paper analyzes the meaning and function of information literacy from the meaning and function of literacy. It is believed that information literacy includes people's cognition, evaluation, control, transcendental literacy and control and restraint consciousness of objective information.

Information literacy puts forward modern information consciousness. It should include the law-abiding consciousness of information value, information security, information consciousness, information morality, information sharing, information, innovation consciousness and information dissemination, and many other aspects.

\section{REFERENCES}

[1] Lipinsld T A, Britz J. Rethinking the Ownership of Information in the $21^{\text {st }}$ Century:E thicalImplications. Ethics and Inform ation Technology. 2000

[2] Wecket J. what is So Bad about Interact Content Regulation?. Ethicsand Information Technology. 2000

[3] Thompson P. B. Privacy, Secrecy and Security. Ethics and Information Technology. 2001

[4] Shirley J. Behrens. A conceptual analysis and historical overview of information literacy. College and Research Libraries. 1994

[5] Ann Wilkinson, Angus Forbes, Jacqueline Bloomfield, etc. An exploration of four web-based open and flexible learning modules in post-registration nurse education. International Jour. of Nursing Studies. 2004

[6] Evelyn J. S. Hovenga Globalisation of health and medical informatics education-what are the issues?. International Jour of Medical In formatics. 2003

[7] Jean Lave \& Etienne Wender Situated Leaning: Legitimate Peripheral Participation.Cambridge Uiversity Press. UK.p.

[8] Joseph D Bronzino. Health Care and Information Ethics: Protecting Fundamental Human Rights. Health Progress. 1999

[9] Tavani. H. T. The State of Computer Ethics As A Philo-sophical Field of Inquiry: So me Contemporary Perspec-tives,Future Projections, and Current Resourcs. Ethics and Information Technology. 2001

[10] Bimber. Three aces of Technological Determinism. Does Technology Drive History?: The Dilemma of Technological determinism. 1994

[11] Burrows S. Developing an "evidence-based medicine and use of the biomedical literature" component as a longitudinal theme of an outcomes-based medical school curriculum: year 1. J Med LibrAssoc. 2003

[12] Mackenzie, J Wajcman. The Social Shaping of Technology. 1999

[13] Brown JF, Nelson JL. Integration of information literacy into a revised medical school curriculum. Med Reference Serv Q. 2003

[14] Tim Jordan. Cyberpower-the culture politics of cyberspace and the internet. 1999 